\title{
Comparative study of postoperative pain in elderly undergoing open hernia repair-spinal anesthesia vs. combined spinal and ilioinguinal block
}

Daniela Ologoiu, Marilena Negoi, Mihaela Vartic, Ana-Maria Cotae, Andreea Scrieciu, Mirela Tiglis, Ioana Marina Grintescu Anesthesiology and Intensive Care Unit, Clinical Emergency Hospital of Bucharest, Romania

\section{Background}

- The incidence of moderate or severe pain in inguinal hernia repair has a frequency from $\mathbf{3 0 - 7 5 \%}$

- Chronic pain is a long-term complication of treating inguinal hernia - mean incidence of $\mathbf{1 1 \%}$

- Illioinguinal / iliohypogastric (IHN) -postoperative analgesia + preventing chronic pain

- This study aimed to compare the efficacy of spinal and IHN block to only spinal block for better postoperative pain relief and extended analgesia in order to prevent chronic pain

Material and Methods

\section{4 patients}

(open inguinal hernia repair)

1. GROUP S (SPINAL)

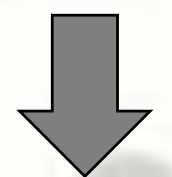

- Premedication: $0.03 \mathrm{mg} / \mathrm{bw}$ Midazolam 10 min before blocks

- Exclusion criteria:

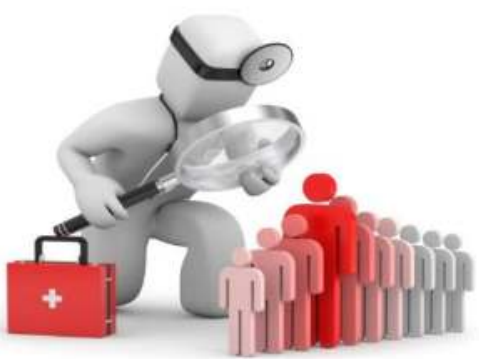

2. GROUP I

(SPINAL+IHN)

SPINAL ANESTHESIA - 77 patients (bupivacaine $0.5 \%-12 \mathrm{mg}$ )

Postoperative pain management: morphine $1 \mathrm{mg}$ bolus at $5 \mathrm{~min}$ until VAS $<40 \mathrm{~mm}$ and after discharge to ward with paracetamol $1 \mathrm{~g}$ at $6 \mathrm{~h}$ and ketorolac $30 \mathrm{mg}$ at $12 \mathrm{~h}$

D Visual analog scale (VAS) scores at rest and cough (in PACU at 4 and 12h) and at rest, cough and movement (at $24,48 \mathrm{~h}$ and 1 month)

Rescue analgesia with oral morphine $5 \mathrm{mg}$ at $6-8 \mathrm{~h}$ for the next $24-48 \mathrm{~h}$

$>$ Home discharge in $48-72 \mathrm{~h}$ with VAS $<40 \mathrm{~mm}$ on coughing and instructed for completion DN4

Pain at 1 month was assessed using the DN4 questionnaire for neuropathic pain

Question 1: Does the pain have one or more of the following
characteristics? 1-Burning 2-Painful cold 3-Electric shocks
Ouestion 2: Is the pain associated with one of more of the following
symptoms in the same area? 4-Tingling 5 -Pins and needles $6-$
Numbness 7-Itching
Ouestion 3: Is the pain located in an area where the physical
examination may reveal one or more of the following
characteristics? 8 - Hypoesthesia to touch $9-$ Hypoesthesia to
prick
Ouestion 4: In the painful area, can the pain be caused or increased
by: $10-$ Brushing
Total score: sum of 10 items and the cut-off value for the diagnosis
of neuropathic pain -total score of $4 / 10$.

\section{Results}
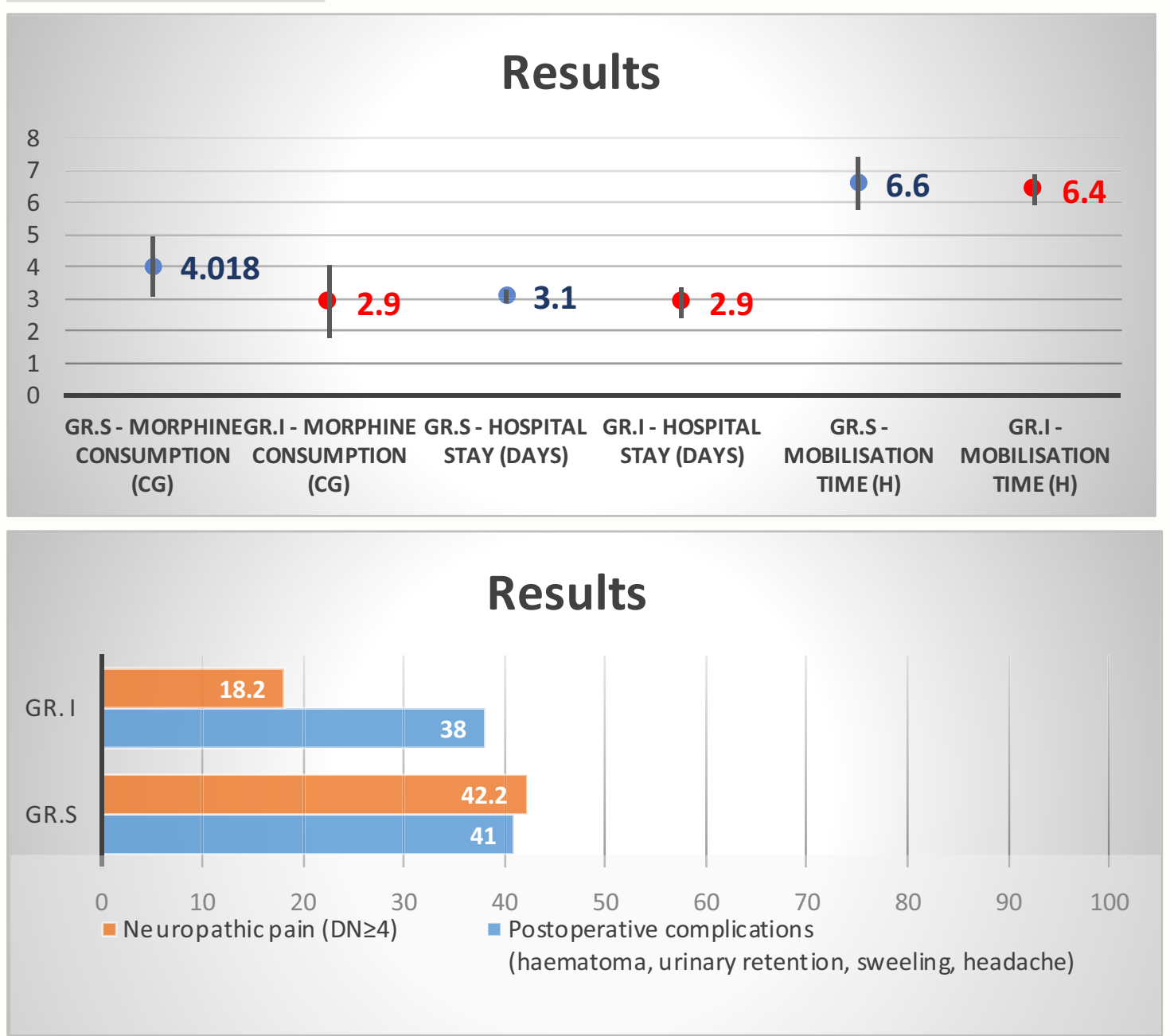

\section{Discussions}

Several limitations: not blinded, no information about other techniques of regional anesthesia, sleep quality, dose of local anesthetics or patients satisfaction.

\begin{tabular}{|c|c|c|c|}
\hline $\begin{array}{c}\text { Patients } \\
\text { characteristics and } \\
\text { surgical data }\end{array}$ & Gr.S & Gr.I & P-value \\
\hline Age (years) & $78 \pm 12.3$ & $80 \pm 13.72$ & 0.862 \\
\hline BMI ( bw / m2) & $25 \pm 3.15$ & $24 \pm 3.78$ & 0.818 \\
\hline ASA ( II/II//V) & $26 / 47 / 4$ & $34 / 41 / 2$ & 0.849 \\
\hline Gender ( M/F) & $75 / 2$ & $74 / 3$ & 0.838 \\
\hline Surgical duration (min.) & $81 \pm 10.12$ & $85 \pm 12.67$ & 0.738 \\
\hline Preoperative pain score (VAS) & $41 \pm 10.11$ & $43 \pm 11.24$ & 0.873 \\
\hline
\end{tabular}

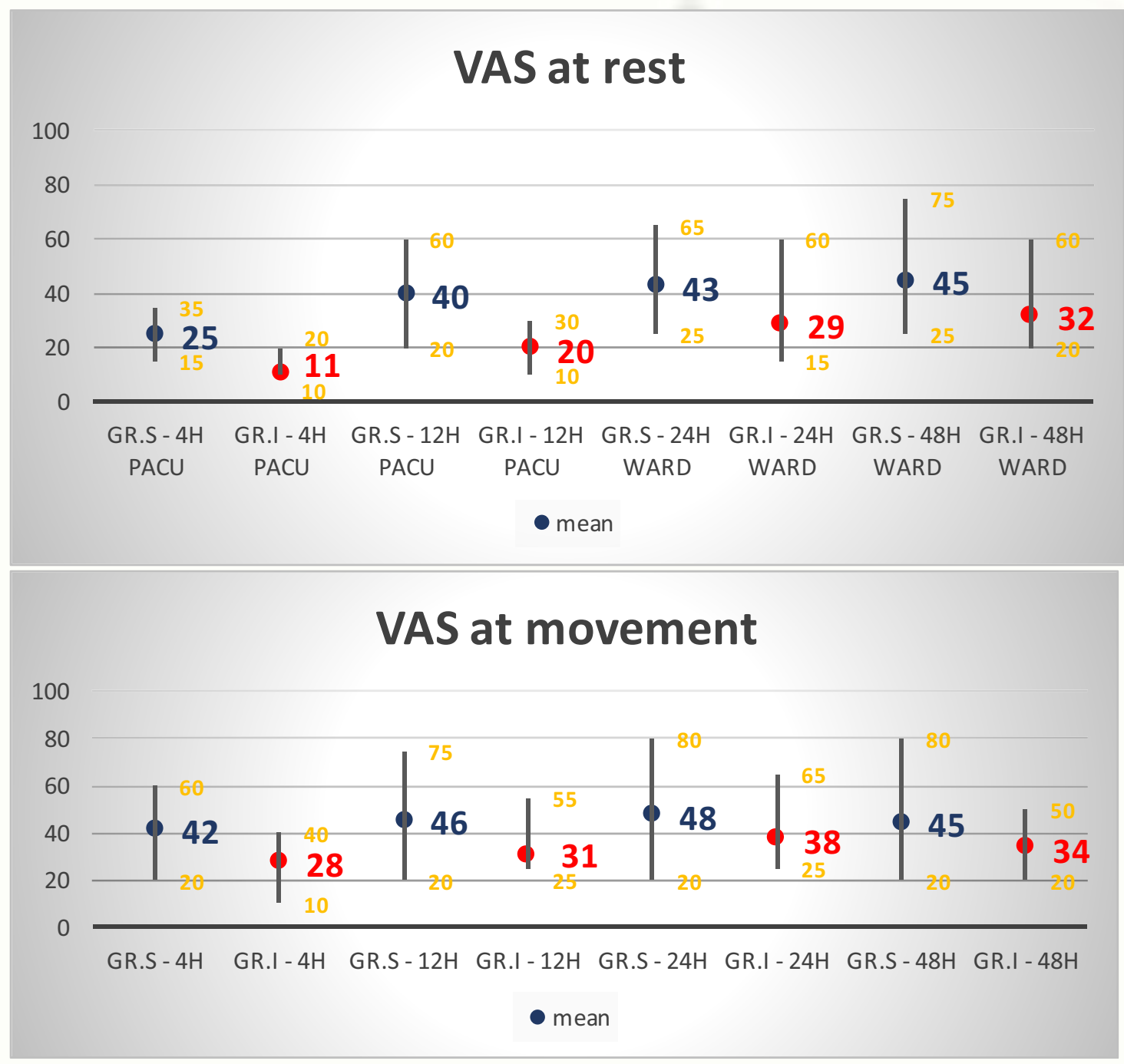

\section{Conclusion}

1. as part of a multimodal analgesia strategy IHN block provides successful perioperative analgesia

2. comparison to only subarachnoid anesthesia, combined spinal with IHN block technique has proved superior and very effective providing better pain control and the occurrence of chronic pain. 